\title{
MORETA, "PUEBLO DE YNDIOS CHICHAS Y TAMBO DEL YNGA" (PUNA DE JUJUY, ARGENTINA)
}

\author{
MORETA, "PUEBLO DE YNDIOS CHICHAS Y TAMBO DEL YNGA" \\ (PUNA OF JUJUY, ARGENTINA)
}

Carlos I. Angiorama ${ }^{1}$, María Josefina Pérez Pieroni ${ }^{2}$ y María Florencia Becerra 3

\begin{abstract}
Resumen
Se presentan los primeros resultados de nuestras investigaciones en el asentamiento de Moreta (Puna de Jujuy, Argentina). Este sitio es mencionado como pueblo de indios chicha y tambo del Inka por el oidor Matienzo en su carta al rey de 1566 . En este trabajo, sintetizamos las investigaciones documentales y de campo realizadas hasta el momento sobre el sitio, y el análisis de parte de la colección recuperada por Márquez Miranda en Moreta durante la década de 1940. De este modo incorporamos un asentamiento de relevancia a la discusión regional, para comprender los procesos sociales ocurridos en el sector norte de la puna jujeña durante los Períodos de Desarrollos Regionales, Inka e Hispano-indígena.
\end{abstract}

Palabras claves: Puna de Jujuy - chicha - inka - casabindo-cochinoca.

\begin{abstract}
The first results of the research conducted in the Moreta settlement, Jujuy province, Argentina, are reported here. This archaeological site is listed in the letter written by Oidor Matienzo as a chicha Indians's settlement and as an inka tambo. In this paper, we summarize the documentary research, field surveys and analysis conducted over part of the collection recovered by Márquez Miranda in the site during the decade of 1940. In this way, we incorporate a settlement of importance to the regional discussion, to understand the social processes occurred in the northern portion of the Jujuy Puna during Regional Development, Inka an Hispanic-indigenous periods.

Keywords: Jujuy Puna - chicha - inka - casabindo-cochinoca.

Recibido: septiembre 2015. Aceptado: marzo 2017.
\end{abstract}

\section{* Introducción}

Desde los primeros estudios en la Puna de Jujuy, uno de los problemas fundamentales a los que los investigadores se abocaron fue el de la identificación de los grupos étnicos que habitaron en ella durante el período prehispáni$\mathrm{co}$, principalmente aquéllos que fueron conquistados por el Inka primero y por los europeos después (p.e. Boman 1908; Vignati 1931). Fue Krapovickas quien sintetizó las distintas propuestas y definió los posibles límites territoriales de cada grupo étnico en la región para los Períodos de Desarrollos Regionales e Inka (900-1535 AD), en base a un análisis documental de fuentes editadas, al que luego sumó los resultados de sus trabajos arqueológicos de campo (Krapovickas 1978, 1983). Así, de acuerdo con su investigación, los casabindo habrían ocupado la sección central y septentrional de la cuenca Miraflores-Guayatayoc-Salinas Grandes, los cochinoca, parcialidad íntimamente relacionada con los primeros, el sur de la Laguna de Pozuelos, mientras que en el norte de esta cuenca y en la subcuenca de Yavi-La Quiaca se habrían radicado grupos chicha (Krapovickas 1978, 1983; Albeck 20082010). Dentro de esta propuesta, se planteó que el valle del Río Grande de San Juan habría albergado grupos de diversas parcialidades que habrían convivido, tal vez, en colonias multiétnicas (Krapovickas 1983; Albeck y Ruiz

\footnotetext{
1 Instituto de Arqueología y Museo, Facultad Ciencias Naturales e IML, UNT-ISES-CONICET. San Martín 1545, (40oo) S. M. de Tucumán, ARGENTINA. Email: carlosangiorama@gmail.com

2 I nstituto de Arqueología y Museo, Facultad Ciencias Naturales e IML, UNT-ISES-CONICET. San Martín 1545, (4000) S. M. de Tucumán, ARGENTINA. Email: josefinaperezp@gmail.com

3 Instituto de Arqueología, Facultad Filosofía y Letras, UBA-CONICET. 25 de Mayo 217 piso 3 (1002), Buenos Aires, ARGENTINA. Email: florenciabecerra@gmail.com
} 
2003). Nuevas investigaciones, sin embargo, están poniendo en cuestión esta propuesta de multietnicidad (Nielsen et al. 2014).

Una de las fuentes más citadas a la hora de dilucidar el panorama étnico de la región puneña es la carta que el oidor Juan de Matienzo escribió en enero de 1566 detallando un camino posible para unir Charcas con el puerto de Buenos Aires. En su listado de tambos y pueblos a lo largo del trazado, Matienzo refiere a "moreta pueblo de yndios chichas y tambo del ynga", a seis leguas de distancia de "casauindo el chico tambo del ynga", junto al cual había indios encomendados a Martín Monje (Levillier 1918: 171). La información brindada por Matienzo no ha pasado inadvertida para varios investigadores quienes, con distintos objetivos, han analizado en profundidad las distancias, descripciones y referencias del oidor en las diferentes versiones publicadas de su carta (p.e. Zanolli 2005; Palomeque 2006; Vitry 2007). En base a ella se ha propuesto que el último pueblo de indios chicha de la Puna de Jujuy, el más meridional, habría sido Moreta (Krapovickas 1978: 87).

A la hora de analizar arqueológicamente a los chicha en territorio puneño, otros sitios han recibido mayor atención, tales como Yavi Chico (Krapovickas 1968), Cerro Colorado 1 o Sansana (Krapovickas y Aleksandrowicz 1986-1987), Pueblo Viejo de la Quiaca (Krapovickas et al. 1989) y Pozuelos (González 1963). Este último, emplazado en un terreno bajo localizado en la margen oriental de la laguna homónima, constituido por viviendas de adobe conformando grandes montículos, ha sido identificado por Albeck (2008-2010) con el topónimo colonial Ichira, y fue señalado como límite sur del espacio ocupado por los chicha (Albeck 2008-2010). La autora plantea que, a pesar de no conocerse la profundidad temporal de los límites prehispánicos, existe una interesante proximidad entre los asentamientos correspondientes a los cochinoca y los asignables a los chicha (Albeck 2008-2010).

Ahora bien, ¿qué lugar ocupaba el pueblo de indios chicha de Moreta en este espacio, si es que fue el poblado chicha más meridional en este sector de la Puna? Un primer punto a resolver es su exacta ubicación geográfica. En 1945 Márquez Miranda llevó a cabo excavaciones en un sitio arqueológico al que llamó Antigal de Moreta. Sin embargo, debido a que el autor no realizó ninguna publi- cación de sus hallazgos y a que no se han encontrado aún notas inéditas que señalen su emplazamiento, no conocemos la localización de ese asentamiento. Unas décadas antes, Boman ya había mencionado el pueblo chicha de Moreta, afirmando que se encontraba al norte de Cochinoca y al oeste de Rinconada, aunque en su mapa lo sitúa al este de esta última localidad, sin dar más detalles del mismo (Boman 1908: 771). En realidad parece no haberlo visitado. En su obra, este investigador describe un sitio al que llama Queta, localizado inmediatamente al sur del bolsón de Pozuelos, ya en la cuenca de Miraflores-Guayatayoc. Muchos años después, Raffino y colaboradores (1986) realizaron una nueva prospección allí, describiéndolo como un tambo inka, con la presencia de Rectángulos Perimetrales Compuestos (RPC), corrales y posibles collcas. Para Raffino (2007: 344), Queta correspondería al tambo de Moreta referido por Matienzo. Vitry (2007), por su parte, ubica tentativamente más al norte Moreta, a menos de $1 \mathrm{~km}$ al sur del paraje El Rodeo, al este de la Laguna de Pozuelos. Allí ha registrado un sitio arqueológico de posible filiación inka, aunque no da mayores detalles al respecto. Asimismo, Albeck (2008-2010) y Albeck y Palomeque (2009), sobre la base del análisis de mercedes de tierras tempranas y otras fuentes documentales, identifican la Pampa de Moreta con la planicie localizada al sur de la Laguna de Pozuelos, al este del río Cince (o Cincel), en las cercanías de la localidad actual de Carahuasi. El tambo de Moreta se localizaría en el abra homónima, "donde ésta se abre hacia el área de la Laguna de Pozuelos" (Albeck 2008-2010: 13).

\section{* Qué dice la documentación histórica SOBRE MORETA}

Como hemos mencionado, fue en el año de 1566 cuando Matienzo se refiere a los indios chicha que atendían el tambo de Moreta y habitaban un pueblo allí mismo. En ese entonces, el tambo de Calahoyo, el siguiente al norte, ya se encontraba despoblado (cf. Palomeque 2006). Siete años después, en 1573, durante la visita del capitán Agustín de Ahumada con el objetivo de reducir en el valle de Talina a los nueve pueblos de Hatun Chichas, la documentación menciona a los indios de Moreta "que estaban ubicados antes de la boca del río que viene de Estarca" (Palomeque 2010: 40). De acuerdo con Palomeque (2010: 44), este "conjunto de pueblos de pastores asentados al norte de Cangrejos que atendían el tambo 
de Moreta" estaban gobernados por Don Diego Espeloca el Viejo, bajo el mando de quien habían derrotado a los chiriguanos en Quera un tiempo antes de haber aceptado la reducción española al valle del río de Talina. Sin embargo, algunos habrían seguido explotando las tierras de pastoreo antiguas, especialmente las de Yoscaba.

En el relato de Ramírez de Velazco en su probanza de méritos y servicios se afirma, por otra parte, que en 1586 , estando en Talina de camino hacia el Tucumán, se enteró de la muerte de un fraile mercedario y dos soldados por "los indios de moreta que estaban de guerra". Por esta razón, envió al capitán Hernán Mejía de Miraval "con veinte hombres de la dicha gente al castigo de lo suso dicho los cuales le hicieron muy exemplar y les quitaron las armas, cauallos y de más cosas que a los muertos auían robado y luego como la dicha gente voluío de lo suso dicho proseguí con toda la dicha gente mi viaje" (Carrizo 2009 [1935]: XX; Krapovickas 1978: 77-78).

Es interesante destacar que esta rebelión de los indios de Moreta ocurrió tan solo 13 años después de la reducción "voluntaria" a Talina. Es más, Francisco Argañaras señala que en 1595, "yendo a correr la tierra encontró un pueblo de yndios que estaua alçado e rreuelado a las espaldas de los yndios de casauindo e que siendo como yndios en grande numero los rrindio con cinco hombres en guerra e los entrego al cura de casauindo e cochinoca" (Levillier 1920: 529), logrando la paz en la región. En otro de los testimonios de los testigos de Argañaras en su probanza de méritos y servicios, se agrega "pueblo de yndios que estaua a las espaldas de casauindo y cuchinoca" (Levillier 1920: 536). Este pueblo "a las espaldas" de los de casabindo y cochinoca, ise refiere efectivamente a indios de estas parcialidades? La indicación de la entrega a su cura haría pensar esto, pero no su ubicación en el espacio como algo separado, como un pueblo que podría corresponder a otro grupo étnico. Recordemos que para el momento en que Argañaras ingresa a la puna aún no se habían fundado los pueblos de reducción en la localización que hoy conocemos, y que podría tratarse por ejemplo, de un pueblo chicha, como el que se había alzado contra el fraile en Moreta. Carrizo, por ejemplo, asume que los rebeldes que son pacificados son casabindo y cochinoca, pero en su relato agrega confusamente que lo estaban "a pesar del escarmiento hecho" (Carrizo 2009 [1935]: XX) por
Mejía de Miraval quien, supuestamente, había controlado a los indios de Moreta, es decir, a un grupo chicha.

Sabemos, por otra parte, que el proceso de ocupación española del territorio puneño estuvo signado por disputas jurisdiccionales entre los vecinos de Charcas y los del Tucumán (Palomeque 2006, 2010, 2013; Sica 2006; Estruch 2013), conflicto que habría generado discursos por parte de estos últimos, exagerando el nivel de agresión y no pacificación de los indígenas de la región, justificando así el avance desde el sur sobre estas tierras, aun cuando documentación previa indicaría acuerdos y negociaciones con la Audiencia de Charcas (cf. Palomeque 2006). Teniendo en cuenta este contexto y los relatos contradictorios sobre el accionar de los indios puneños, es difícil interpretar la veracidad de los alzamientos, tanto de Casabindo y Cochinoca, como el de los Chicha en el territorio en disputa. Sin embargo, en caso de que efectivamente los indios de Moreta hayan atacado a los viajeros en 1583, a pesar de haber sido reducidos en Talina, se corroboraría lo que ha planteado Palomeque (2010; 2013) en relación a la continuidad de la ocupación chicha del territorio puneño tiempo después del proceso de reducción ocurrido diez años antes, y, por tanto, la aparente presencia, al menos esporádica, de indígenas en el pueblo chicha emplazado junto al tambo de Moreta.

\section{* Avances de investigación en moreta}

Hace una década comenzamos nuestras investigaciones en el sector sur de la cuenca de Pozuelos (Figura 1). Uno de los objetivos que guiaron nuestro trabajo fue evaluar cómo las conquistas inka y española habían impactado en diversos aspectos de la población local (en sus modos de vida, en la forma de ocupar el territorio, en la manera de relacionarse con habitantes de otras regiones, etc.). La elección del área de estudio cobraba sentido habida cuenta de que el asentamiento principal de la cuenca, el Pukara de Rinconada (al cual se habían limitado las investigaciones arqueológicas hasta ese entonces), había sufrido importantes remodelaciones en época inka, y porque un ramal del Qhapaq Ñan, aquél por el que ingresaron los primeros europeos al actual Noroeste Argentino, atravesaba de norte a sur el bolsón de Pozuelos. Nuestra área de estudio incluía el abra de Moreta, localizada en la Sierra de Cochinoca, y que comunica la cuenca de Pozuelos con la de Miraflores-Guayatayoc, al este. Las 


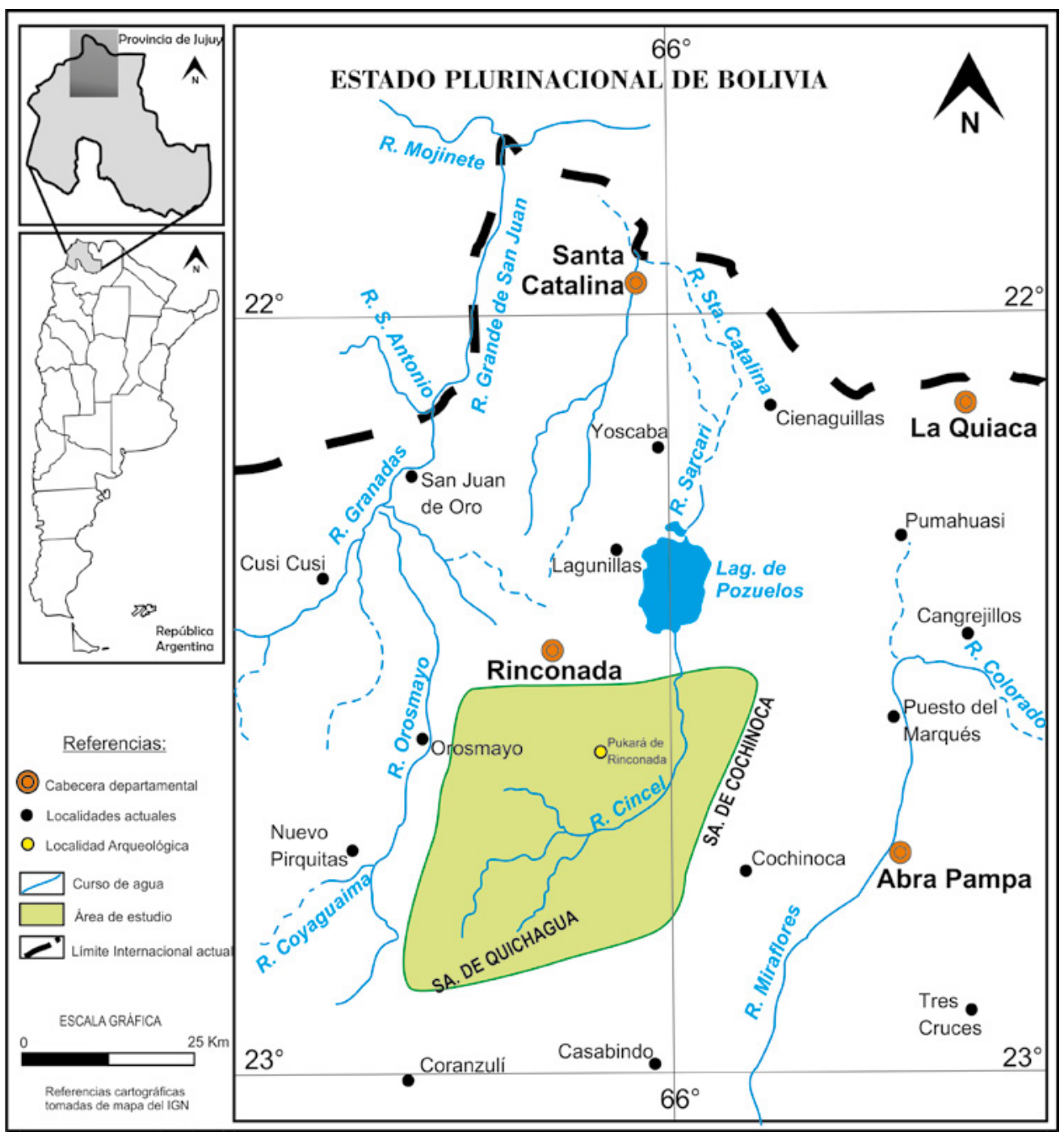

Figura 1. Área de estudio: sector sur de la cuenca de Pozuelos (Puna de Jujuy, Argentina). Mapa confeccionado por Silvina Rodríguez Curletto.

prospecciones realizadas en ese sector nos permitieron identificar una serie de estructuras arqueológicas que interpretamos como el poblado y tambo de Moreta mencionado por Matienzo en su carta.

El asentamiento está compuesto por un RPC de planta cuadrangular, de $60 \mathrm{~m}$ de lado, con dos series de recintos de planta rectangular construidos en su interior, alineados contra dos de sus lados, sin comunicación interna entre ellos y con salida al patio interno: cuatro contra el muro noroccidental (todos de unos $15 \times 12 \mathrm{~m}$ ), y cuatro más contra el muro nororiental (uno de 19 x $10 \mathrm{~m}$ y los tres restantes de 10 x 10 m; ver Figura 2 A). Adosada al muro nororiental, hacia el exterior del RPC, se construyó una terraza de planta rectangular, de unos $20 \times 7 \mathrm{~m}$, que configura un espacio sobreelevado respecto al terreno circundante.

A unos $50 \mathrm{~m}$ al noreste del RPC se levantaron una serie de terrazas de muros de factura muy cuidada, que horizontalizan un terreno que originalmente presentaba una leve pendiente (Figura 2 B). Este sector culmina en las barrancas de un curso de agua temporario que en algunos lugares alcanza los $6 \mathrm{~m}$ de ancho, y que divide en dos el asentamiento. La superficie del sector aterrazado alcanza i ha aproximadamente. No se observan subdivisiones 


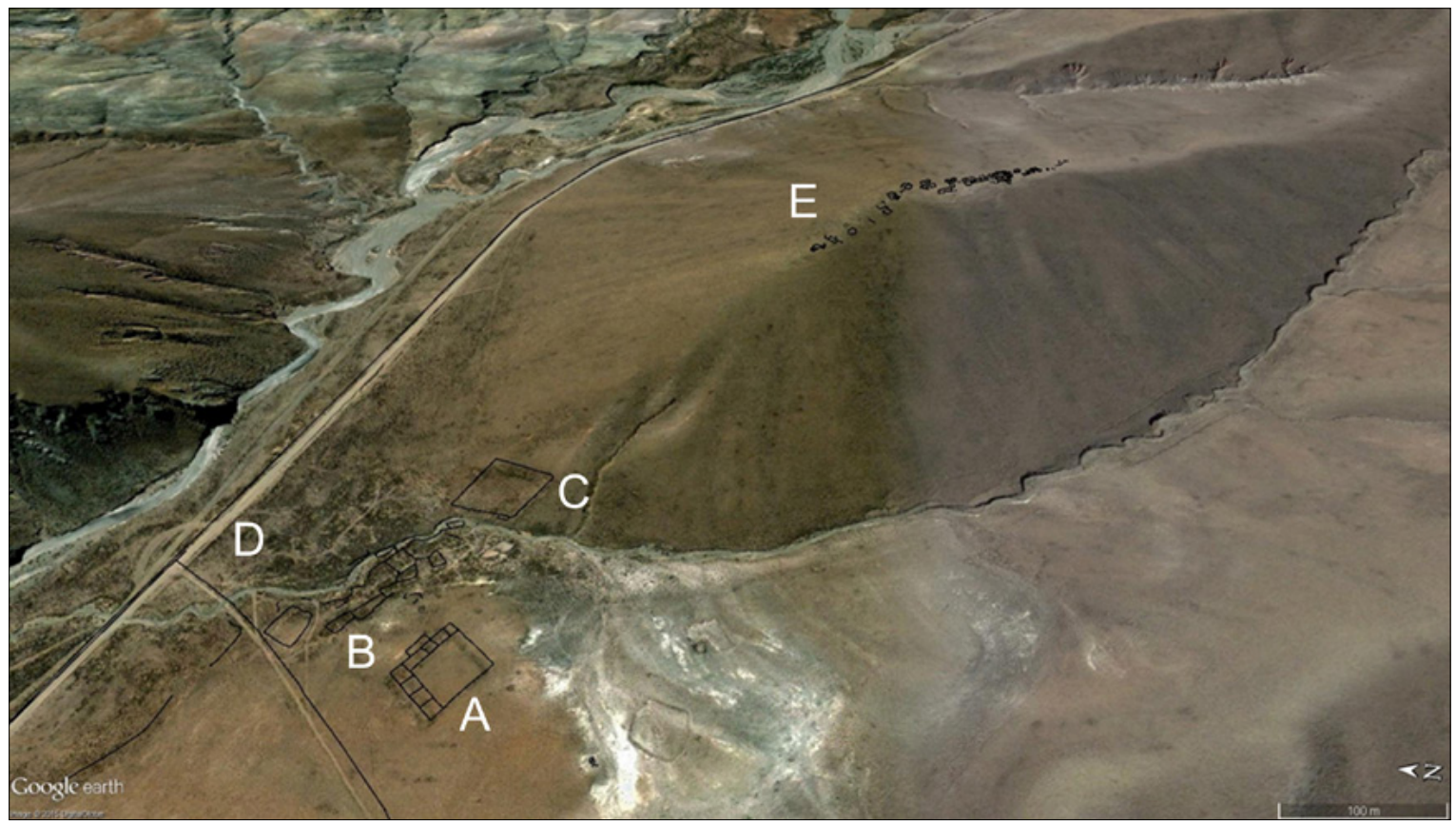

Figura 2. Imagen satelital de Moreta, con algunas de las estructuras relevadas. A: RPC; B: sector aterrazado; C: corral; D: sector con arquitectura chicha; E: sector en la cima de la loma.

internas en las terrazas y el sedimento superficial presenta un alto contenido de ceniza y carbón. Inmediatamente al este de las terrazas, junto a una vivienda subactual, se conserva un antiguo corral de planta aproximadamente cuadrangular, de $60 \mathrm{~m}$ de lado, con un recinto de planta rectangular de unos 9 × $4 \mathrm{~m}$ adosado en una de sus esquinas hacia el exterior (Figura $2 \mathrm{C}$ ). Hacia el sur, aguas arriba del curso temporario ya mencionado, se conservan otros cuatro corrales antiguos, algunos de los cuales superan en tamaño al ya referido.

Frente a las terrazas que se extienden al noreste del RPC, del otro lado del curso de agua, hacia el norte, una serie de recintos se aglutinan en una superficie de 1,5 ha aproximadamente (Figura 2 D). En los casos en los que las características arquitectónicas se observan con mayor claridad, se registran recintos de planta rectangular construidos en torno a un patio central aproximadamente cuadrangular, delimitado por un muro bajo, construido con anterioridad a las estructuras que lo rodean. En ocasiones los recintos se adosan a dos de los lados del patio, configurando una L, mientras que en otras oportunidades se construyeron en torno a tres de los bordes del patio, configurando una U. Se trata de un patrón en todo comparable al de las viviendas chicha del valle del Río Grande de San Juan (Nielsen et al. 2014). En superficie se observan tanto muros dobles con relleno como muros simples, conformando los espacios techables. A orillas del curso temporario hemos detectado un potente basurero, erosionado en parte por el agua de escorrentía, y junto a una de las unidades habitacionales, en un espacio extramuros, hemos registrado una cista de paredes de piedras, subterránea, abierta y vacía, de aproximadamente $1 \mathrm{~m}$ de diámetro y $1 \mathrm{~m}$ de profundidad. A diferencia de lo que ocurre en el RPC y en los sectores aterrazados, la superficie de esta porción del asentamiento se encuentra cubierta de fragmentos cerámicos, a los que se suman material lítico tallado, restos óseos de fauna y palas de piedra, enteras y fracturadas. En algunas de las estructuras de este sector del asentamiento se observan evidencias de antiguas excavaciones, que probablemente correspondan a las realizadas en el sitio por Márquez Miranda en 1945.

A pocos metros al este del asentamiento, se localiza una loma que se eleva unos $120 \mathrm{~m}$ respecto a la cota del poblado. Su ladera promedia una pendiente de un $30 \%$. En su cima, muy angosta, ha sido edificado un conjunto de recintos de plantas cuadrangulares o rectangulares, dispuestos en hilera, algunos de los cuales presentan adosadas 


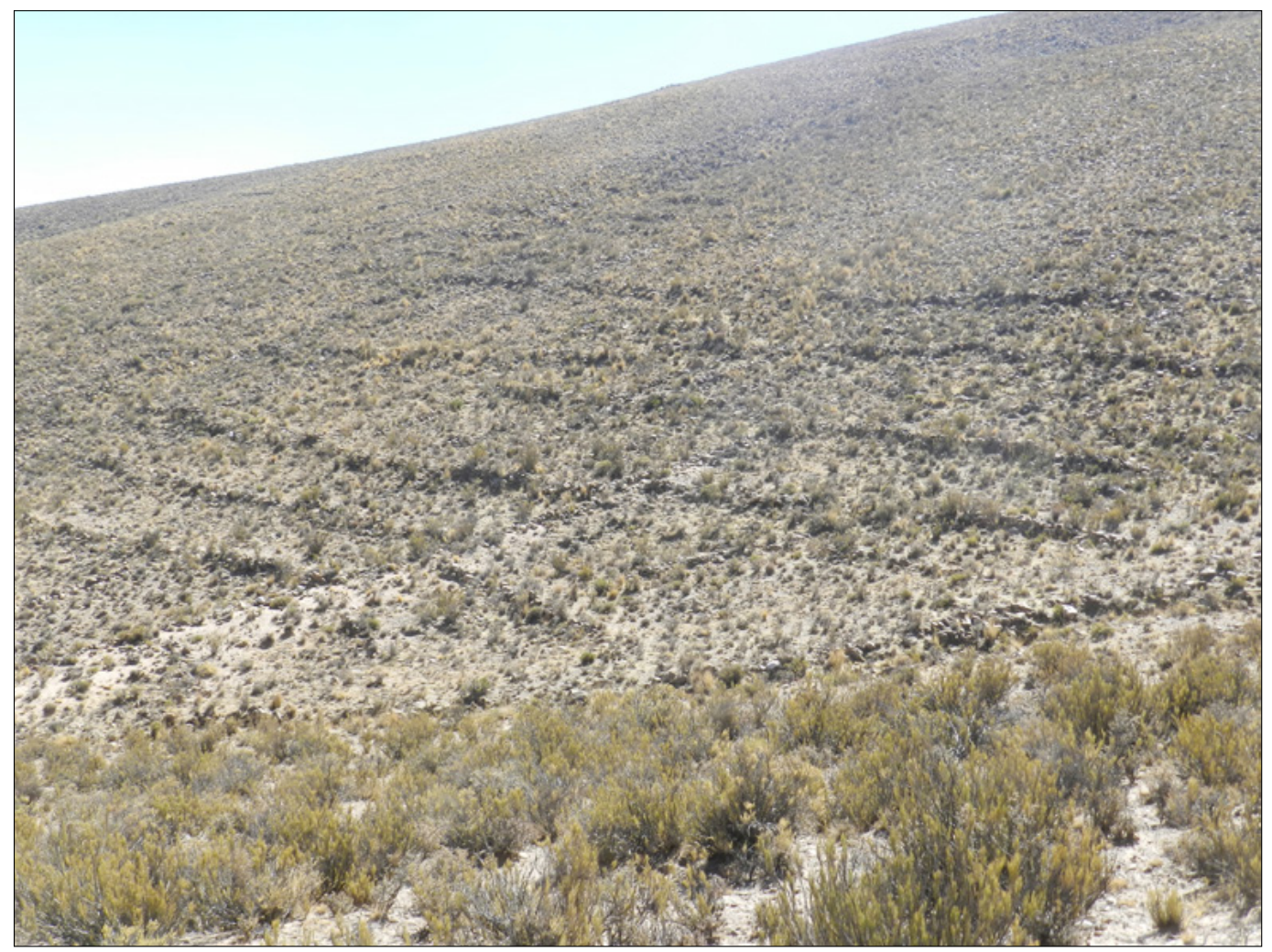

Figura 3. Estructuras agrícolas de Moreta.

terrazas y muros de contención (Figura 2 E). De acuerdo con las características arquitectónicas observadas en superficie, estimamos que unas treinta de las estructuras corresponden a recintos que habrían estado techados. Entre algunos de ellos se observa un pasillo para la circulación. En el sector medio del agrupamiento de estructuras, donde el ancho de la cima lo permitía, se edificó una vivienda que responde claramente al patrón chicha ya mencionado. Consiste en una serie de recintos de planta rectangular construidos en torno a un patio central de planta cuadrangular. A lo descripto se suman otros muros de contención aislados y ocho estructuras (la mayoría de planta circular, alguna de planta rectangular), de poco más de $1 \mathrm{~m}$ de diámetro, posiblemente depósitos construidos sobre el nivel del suelo. Todas las edificaciones mencionadas han sido levantadas en la cima de la loma, ocupando una superficie de unos $300 \mathrm{~m}$ de largo y $25 \mathrm{~m}$ de ancho máximo. A pesar de carecer de arquitectura militar, por su emplazamiento topográfico y la disposición de las estructuras este sector adquiere un marcado carácter defensivo. En superficie hemos hallado tan solo unos pocos fragmentos cerámicos sin tratamiento de superficie.
Finalmente, a $1 \mathrm{~km}$ hacia el sudoeste del RPC, sobre la ladera occidental de las últimas lomadas de la Sierra de Cochinoca, se emplazan una serie de andenes y terrazas de cultivo que se extienden luego hacia el sur, ocupando gran parte de cada una de las laderas orientadas hacia el bolsón de Pozuelos, hasta la latitud de la localidad de Carahuasi, a unos $3,5 \mathrm{~km}$ al sur del RPC de Moreta (Figura 3). En algunos sectores, a los andenes y terrazas se suman melgas en las porciones de menor pendiente. La superficie ocupada por esta infraestructura agrícola supera las 100 ha, y hasta el momento hemos hallado entre los campos de cultivo apenas dos estructuras que parecen haber sido recintos habitacionales. Las características constructivas y la magnitud de esta superficie agrícola no tienen parangón en el resto del sur de Pozuelos. Por su escala, diseño y factura es muy probable que daten de tiempos incaicos. En este sentido, es de destacar que se emplazan junto al Qhapaq Nan que atraviesa Pozuelos de norte a sur por el fondo de la cuenca, cercano a las últimas estribaciones de la Sierra de Cochinoca. 


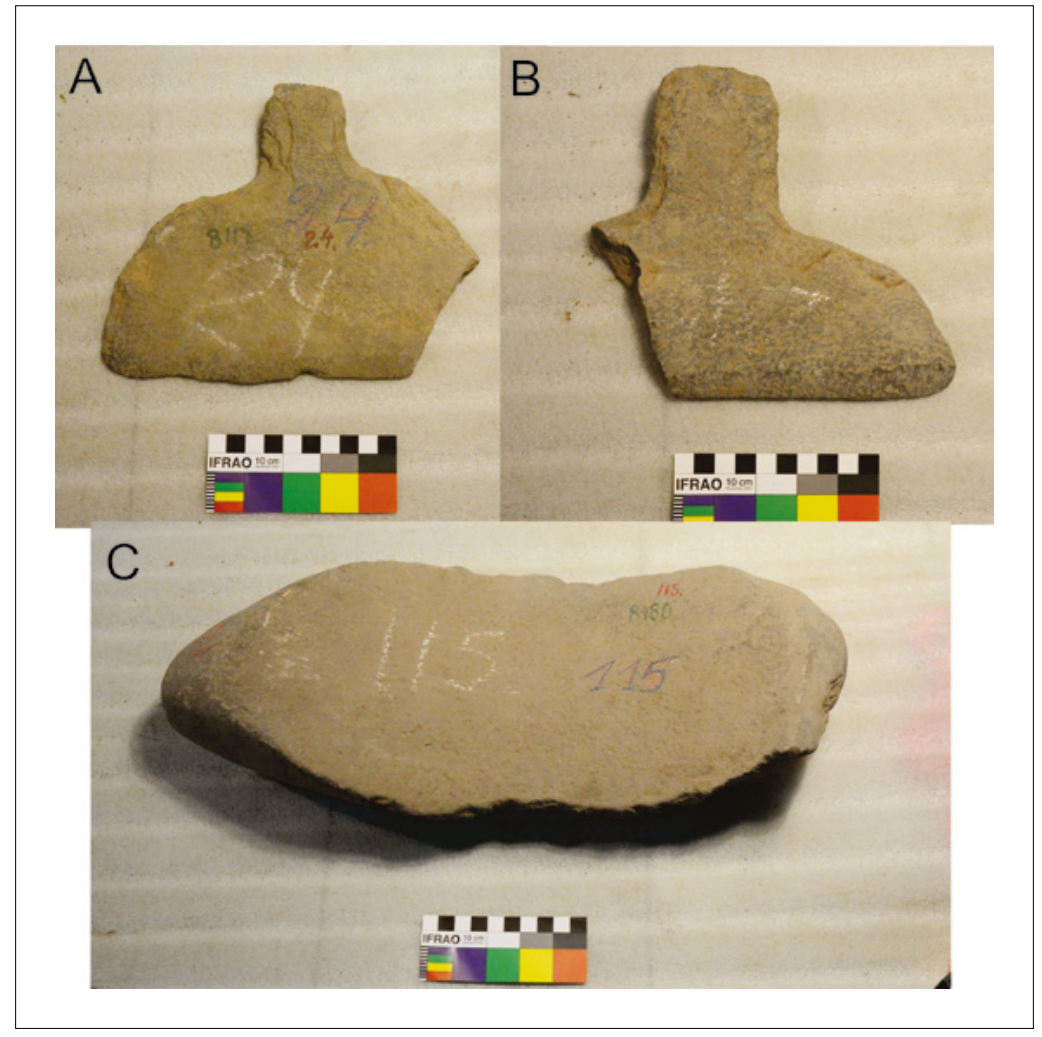

Figura 4. Piezas líticas de la colección Márquez Miranda. A: MLP-D25-CMM-No(v)8117/(r)24; B: $\mathrm{N}^{\circ}(\mathrm{v}) 8263 /(\mathrm{r}) 240$ y C: $\mathrm{N}^{\circ}(\mathrm{v}) 8180 /(\mathrm{r}) 115$.

\section{* La colección márquez miranda PROVENIENTE DE MORETA}

Los objetos hallados a comienzos del año 1945 por Márquez Miranda en Moreta se encuentran hoy resguardados en los Depósitos 6/7 y 25 del Museo de Ciencias Naturales de la Universidad Nacional de La Plata. No existen publicaciones que refieran a la investigación realizada, y las anotaciones de campo no han sido halladas aún. En consecuencia, no conocemos qué tipos de contextos fueron excavados, ni las asociaciones entre las piezas recolectadas. Solamente contamos con la información volcada en las fichas de catalogación del material, que consiste en el tipo de material hallado, una pequeña descripción de la pieza y, en algunos casos, el dato de la profundidad del hallazgo.

La colección Moreta obtenida por Márquez Miranda consiste en 267 objetos y/o lotes registrados. Éstos incluyen material lítico, tales como palas, instrumentos de molienda y cuentas de variados tamaños; un fragmento de asta de ciervo, cinco objetos de metal y 73 recipientes cerámicos. El material provendría fundamentalmente de contextos de habitación del sector del asentamiento con arquitectura chicha, donde hemos observado evidencias de excavaciones antiguas.

El material lítico. La mayoría de los objetos de la colección han sido confeccionados con piedra. De estos 152 objetos, 96 son palas, 61 son instrumentos de molienda (manos de moler, conanas, y morteros, etc.) (Figura 4), y 13 son cuentas de formas y tamaños diversos, elaboradas en toba volcánica, sílices y minerales de cobre. ${ }^{4}$

Los objetos metálicos. Márquez Miranda recuperó cinco objetos metálicos en Moreta: tres cinceles, una cadena y un fragmento de un objeto no identificado, con filo en uno

4 Una porción de la muestra de palas líticas $(n=6)$ ha sido analizada por Hugo Yacobaccio (1983) como parte de un estudio funcional de azadas líticas. Actualmente Julio Ávalos se encuentra estudiando este material, por los que solo haremos una breve descripción del mismo. 


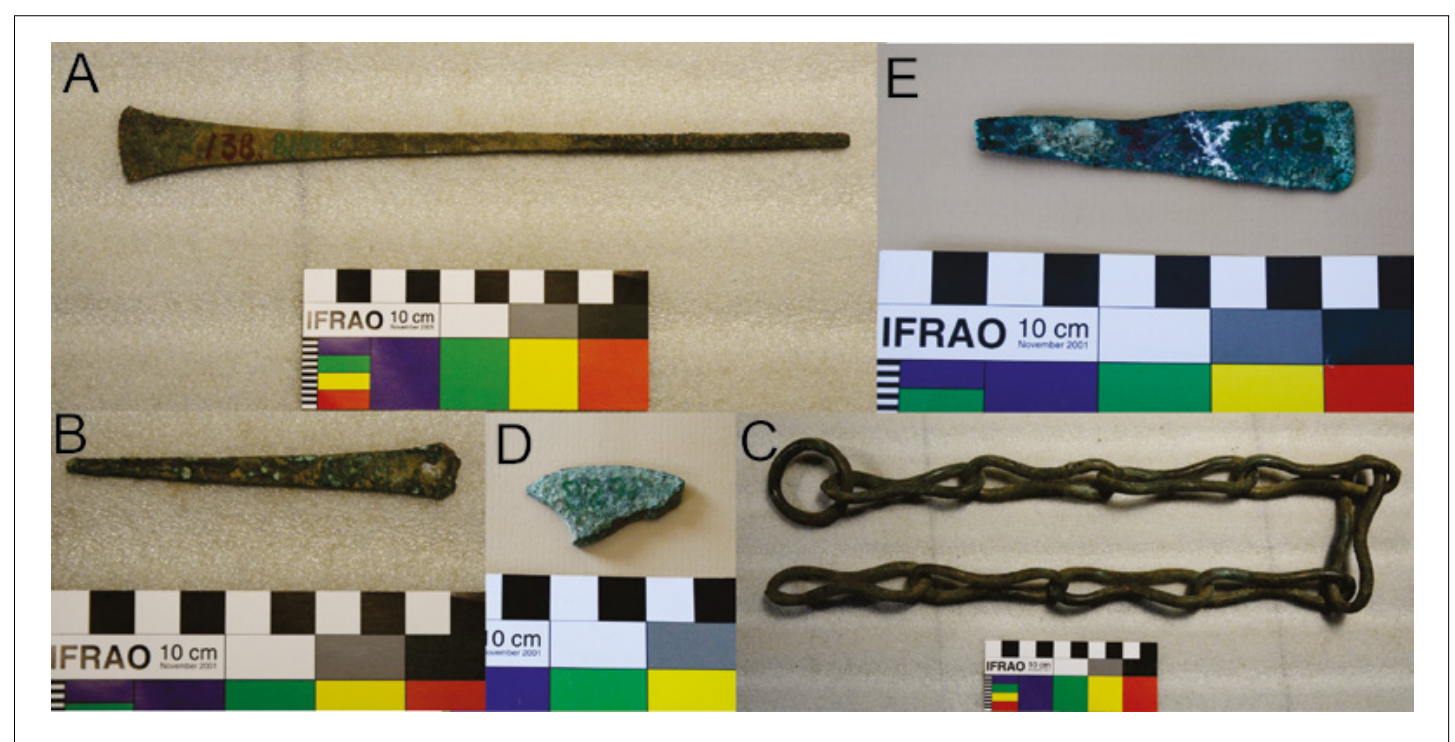

Figura 5. Objetos metálicos de la colección Márquez Miranda. A: MLP-D25-CMM-No(v)8191/(r)138; B: No(v)8178/(r) 112; C: No(v)8124/(r) 39; D: D6-7-CMM- No(v)8291/(r)277 y E: No(v)8105/(r)7.

de sus bordes. Todos han sido manufacturados con cobre como metal base (Figura 5). Uno de los cinceles se encuentra fragmentado en su extremo más angosto, mientras que los otros dos se conservan completos. La cadena consta de diez eslabones y alcanza una longitud total de $77,5 \mathrm{~cm}$. Uno de los eslabones tiene forma circular, mientras que los restantes presentan forma de 8 . En cuanto al último objeto, la morfología del fragmento y la ubicación del filo en uno de sus bordes más largos, nos hacen suponer que podría haber formado parte de un cincel de filo ancho o de un hacha plana.

El material cerámico. Del total de piezas de la colección, 73 corresponden a materiales cerámicos, incluyendo recipientes completos y algunos lotes de fragmentos. Pudimos localizar y registrar 66 de ellos, para los cuales relevamos atributos morfológicos, estilísticos y tecnológicos, en planillas diseñadas en nuestros trabajos previos con materiales de colección (Pérez Pieroni 2013).

Los materiales cerámicos registrados corresponden a recipientes de distintas morfologías, que hemos clasificado siguiendo a Balfet et al. (1992). Como se observa en la Tabla 1, hay una amplia diversidad de formas, predominando las abiertas. Para 16 fragmentos, de diferentes tamaños y procedentes de diversas porciones morfológicas de las vasijas, no se han podido determinar

\begin{tabular}{|c|c|}
\hline FORMA & $\mathbf{N}^{\circ}$ \\
\hline 1.1 plato & 1 \\
\hline 1.2 fuente & 1 \\
\hline 1.3 escudilla o puco & 16 \\
\hline 1.4 escudilla honda & 6 \\
\hline 1.5 cuenco & 1 \\
\hline 1.6 vaso & 4 \\
\hline 1 abiertas indeterminadas & 2 \\
\hline 2.1 vasija & 5 \\
\hline 2.1 taza & 1 \\
\hline 2.3 botella & 1 \\
\hline 2.3 aríbalo/aribaloide & 5 \\
\hline 2 cerradas indeterminadas & 4 \\
\hline Miniaturas & 1 \\
\hline Formas varias & 2 \\
\hline Indeterminadas & 16 \\
\hline
\end{tabular}

Tabla 1. Morfologías de los recipientes cerámicos de la Colección Márquez Miranda. 


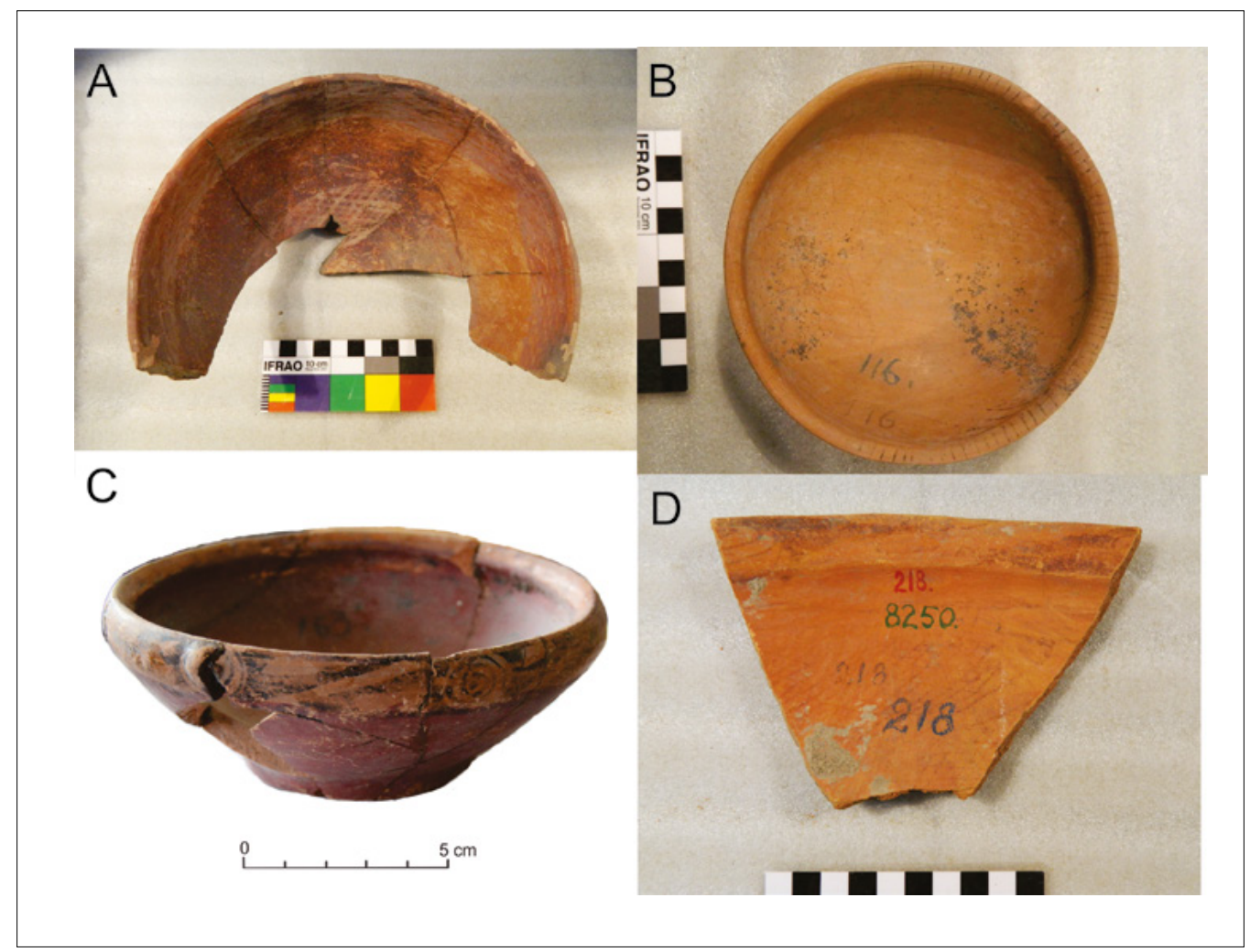

Figura 6. Piezas cerámicas de la colección Márquez Miranda vinculables al estilo Yavi-chicha. A:MLP-D25-CMM$\mathrm{N}^{\circ}(\mathrm{v}) 8_{131} /(\mathrm{r}) 52 ; \mathrm{B}: \mathrm{N}^{\circ}(\mathrm{v}) 8181 /(\mathrm{r}) 116 ;$ C: D6-7-CMM-No(v)8208/(r)163 y D: D25-CMM-No(v)8250/(r) 218.

las formas correspondientes. A otros dos los hemos clasificado como "formas varias", incluyendo una base con asa interna y un objeto macizo fragmentado con una perforación transversal.

Del total de los materiales cerámicos analizados, un número importante se trata de piezas que corresponden a lo que en la literatura previa se ha denominado estilo Yavi-chicha $(\mathrm{n}=22)$. Este estilo se caracteriza por presentar diversas morfologías abiertas y cerradas; por su decoración, consistente en superficies bien pulidas y engobadas en rojo, morado o ante, con la presencia en ocasiones de motivos geométricos pintados en negro "desleído" sobre el engobe o fondo de la pasta; y por el aspecto macroscópico de las pastas, que suelen ser compactas, con colores rojos, rosados o anaranjados, y que frecuentemente presentan inclusiones blancas visibles macroscópicamente consistentes en rocas pelíticas (Krapovickas 1965, 1975, Krapovickas et al. 1989; Ávila 2008; Cremonte et al. 2007; Pérez Pieroni 2013). Este estilo cerámico ha sido relacionado por Krapovickas (1983) con el grupo etnográfico chicha.
En la muestra analizada, los recipientes que corresponderían a este estilo incluyen mayormente contenedores abiertos (Figura $6 \mathrm{~A}, \mathrm{~B}$ y $\mathrm{C}$ ), tales como escudillas o pu$\cos (n=9)$, escudillas hondas $(n=2)$, un cuenco, un plato y un recipiente con un diámetro estimado de $43 \mathrm{~cm}$, posiblemente una fuente (Figura 6 D). Sus superficies han sido pulidas o pulidas y engobadas, pudiendo presentar también pintura negra desleída, en motivos de campos rellenos con reticulado, triángulos con espirales y otros, todos previamente documentados para este estilo alfarero (Krapovickas 1965, 1975, Krapovickas et al. 1989; Ávila 2008).

Los recipientes cerrados incluyen un pelike (Figura 7 D), con pintura negra desleída sobre engobe rojo, formas de aríbalo o aribaloides $(n=4)$, y un contenedor cerrado para el cual no se puede determinar la forma específica. Además hay dos piezas de morfología indeterminada, con las superficies engobadas y pulidas. Dentro de este grupo, hay un número de recipientes que presentan características morfológicas que los vinculan a la presencia inka en 


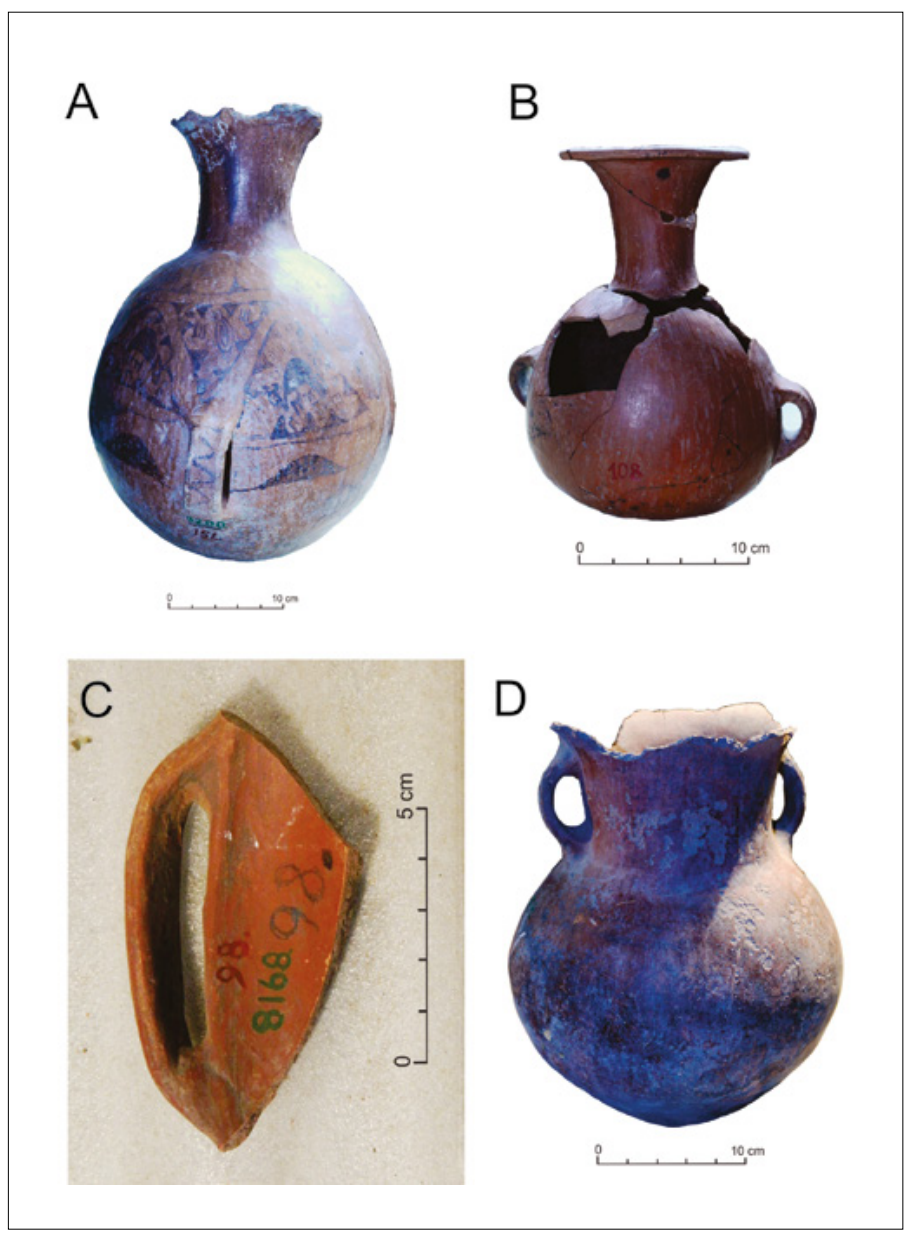

Figura 7. Recipientes cerámicos de la colección Márquez Miranda de estilo Yavi-chicha con morfologías inkaicas. A:D25-CMM-No(v)8200/(r)151; B: No(v)8176/(r)108; C: No(v)8168/(r) 98 y D: No(v)8184(r)121.

la región, y que corresponderían a recipientes Inka provincial $(n=5)$ (sensu Calderari y Williams 1991). Incluyen los cuatro recipientes cerrados de morfología aribaloide (Figura 7 A y B) y un fragmento de escudilla con asa labio adherida (Figura $7 \mathrm{C}$ ).

Un fragmento con un punto de inflexión presenta improntas de textil en la superficie externa y podría vincularse al estilo "Pozuelos con cuarzo", que ha sido relacionado con la cerámica del estilo Yavi-chicha (Krapovickas 1975; Krapovickas et al. 1989). Otros recipientes son comparables a morfologías que han sido más vinculadas con el estilo Casabindo o Agua Caliente (Ottonello 1973; Albeck 2001; Pérez Pieroni 2013), incluyendo pucos interior negro pulido $(n=3)$ (que son abundantes en todos los sitios de la puna analizados hasta la fecha e incluso están presentes en la Quebrada de Humahuaca; Nielsen
1997), vasos chatos $(n=4)$, un fragmento de base de un recipiente de morfología indeterminada con orificios en la base, que pudo ser usado de manera similar a los vasos chatos, un recipiente restringido con asa lateral tipo taza, y un fragmento de base con un asa interna (Figura 8). Sin embargo, representan una porción menor de la muestra que los recipientes vinculados al estilo Yavi-chicha, y notoriamente no están presentes ciertos tipos de recipientes muy característicos, como aquellos con decoración Casabindo bicolor y tricolor, o las diversas morfologías de vasijas que se han definido dentro de este estilo.

Otro conjunto de recipientes está integrado por piezas ordinarias o de estilo indeterminado $(n=22)$, consistentes en escudillas o escudillas hondas $(n=4)$, vasijas $(n=2)$, una vasija miniatura, dos recipientes cerrados de morfología indefinida, un objeto macizo con una perforación 


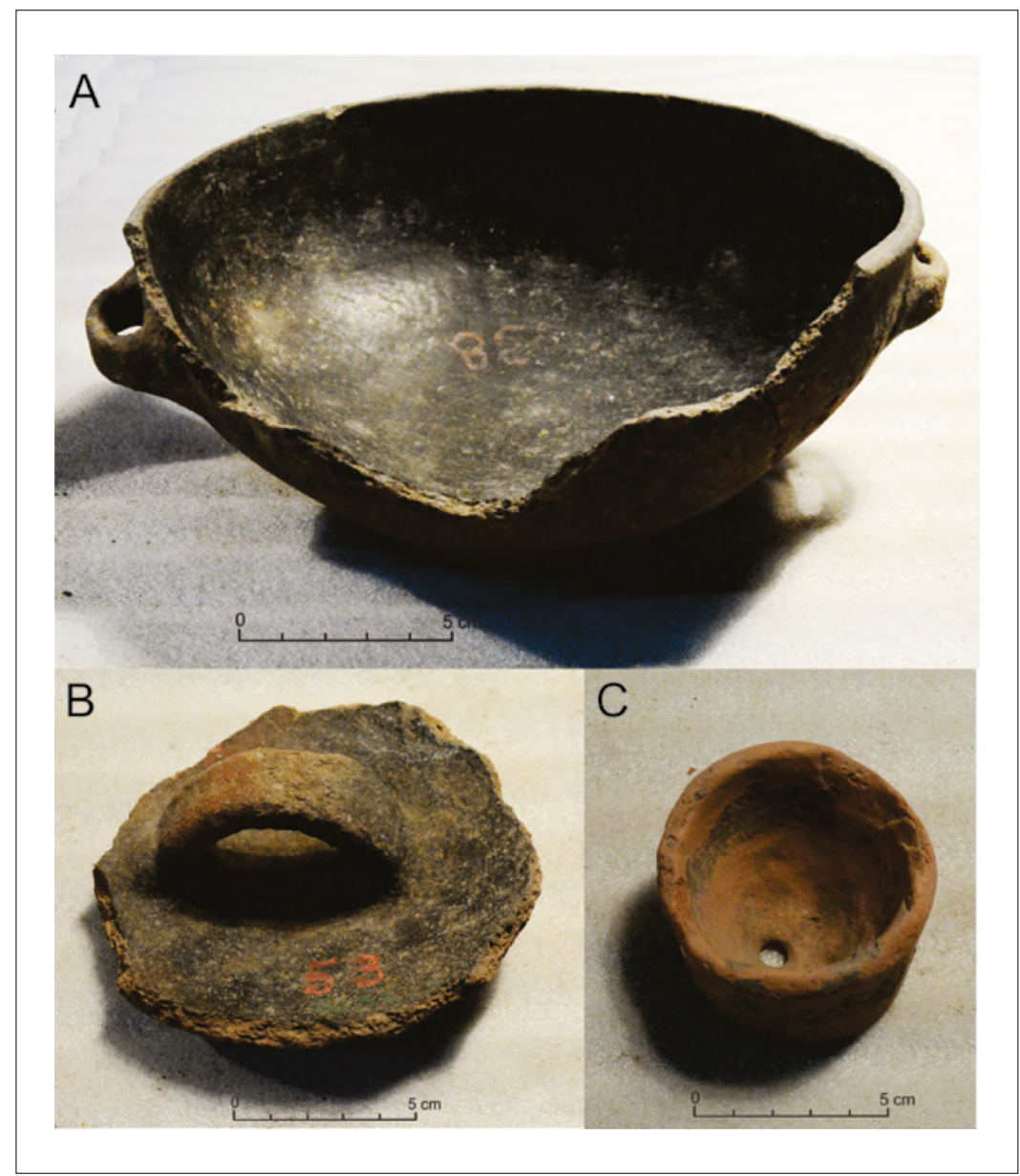

Figura 8. Piezas cerámicas de la colección Márquez Miranda de morfologías comparables a las definidas para el estilo Casabindo. A:MLP-D25-CMM-No(v)8123/(r)38; B: No(v)8132/(r) 53 y C: No(v)8272/(r) 249.

transversal, y un conjunto de materiales fragmentarios, para los que no se pudo precisar su morfología $(n=12)$. Presentan sus superficies mayormente alisadas y, en algunos casos, pulidas.

Ciertos materiales cerámicos que integran la colección procederían de zonas externas a la Puna de Jujuy, tanto por sus morfologías como por sus acabados de superficie $(\mathrm{n}=10)$. Siete además presentan morfologías relacionables a la presencia imperial, varias $(n=4)$ de las cuales presentan sus superficies negras y pulidas, incluyendo dos escudillas pequeñas exactamente iguales entre sí (Figura 9 A), un fragmento de una posible aisana o puchuela, y una botella pequeña, a la que le falta el cuello y el borde. También se registró un fragmento de escudilla con apéndice ornitomorfo y otra con apéndice modelado y decoración de círculos concéntricos en negro y blanco en la superficie interna (Figura
$9 \mathrm{C})$, que probablemente también tuvo un apéndice ornitomorfo, dado que se observan los restos de una inserción adherida en el extremo opuesto al modelado. Una vasija de superficies alisadas presenta un cuello corto cilíndrico, una base troncocónica y un asa lateral, morfología que puede vincularse también a la presencia imperial. Finalmente, un fragmento de cuello de un recipiente cerrado presenta decoración en negro sobre el fondo de la pasta, con una cruz en negativo inscrita en un triángulo, que posiblemente corresponda a un recipiente Inka provincial de procedencia indeterminada (Figura 9 B).

Por último, dos recipientes abiertos (una escudilla o puco y una escudilla honda) presentan decoración interna en negro sobre fondo rojo, que permiten vincularlas a los estilos Tardíos de la Quebrada de Humahuaca (Nielsen 1997). Uno de ellos se ilustra en la Figura 9 D. 


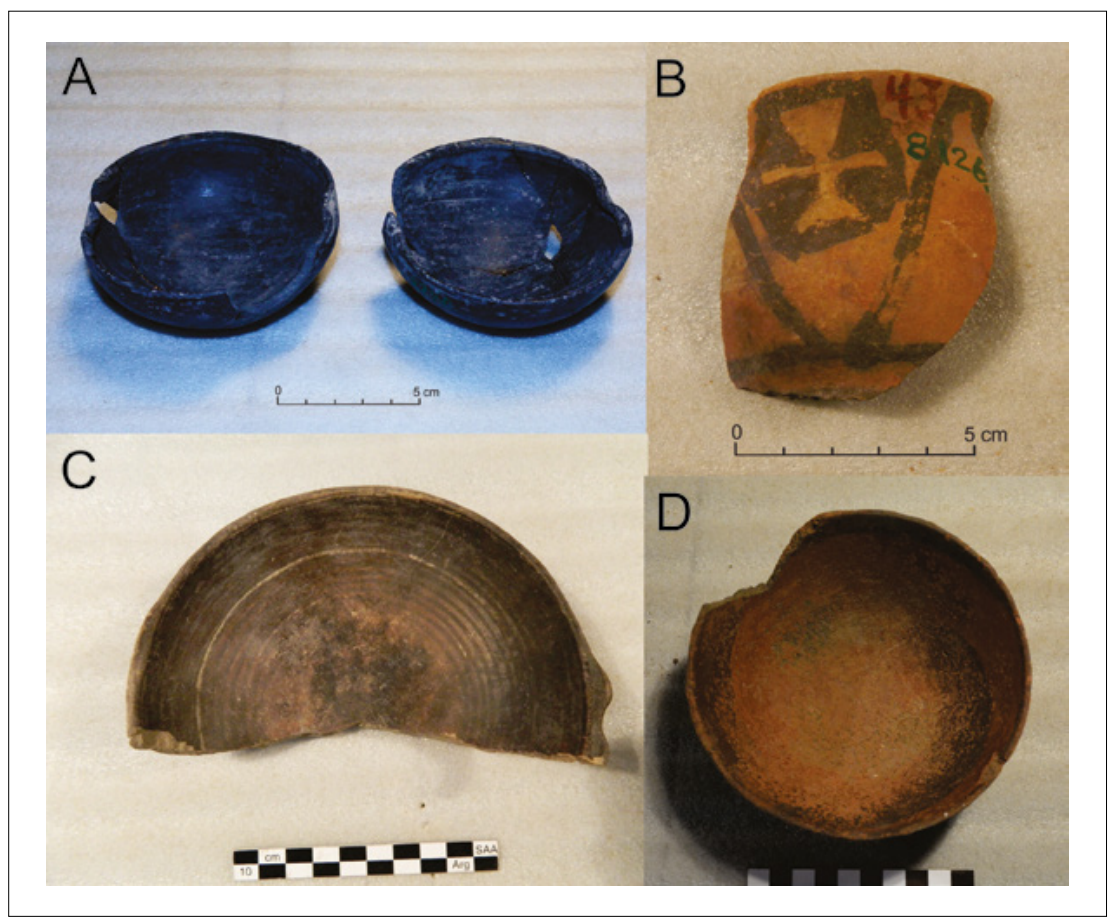

Figura 9. Recipientes cerámicos procedentes posiblemente de zonas externas a la Puna de Jujuy. A: MLP-D25CMM-No(v)8279/(r)261; No(v)8280/(r)262; B: No(v)8126/(r) 43; C: No(v)8173/(r)104 y D: No(v)8107/(r)10.

\section{$*$ Consideraciones acerca de la colección MÁRQUEZ MIRANDA DE MORETA}

Los objetos más abundantes de la colección son los confeccionados con material lítico. De este conjunto, las palas de Moreta no presentan ninguna particularidad que las diferencie de otras halladas en la Puna de Jujuy. De acuerdo con sus materias primas, morfologías, dimensiones y huellas de desgaste corresponden a dos de los tipos de palas líticas definidos por Ávalos: "triangular alargado, donde el ancho es aproximadamente el doble de largo" y "trapezoidal, donde el largo es casi igual al ancho", ambas con pedúnculo rectangular (Ávalos 1998: 293). Algunas han sido utilizadas con un mango curvo, a modo de azada, mientras que a otras se les agregó un mango recto, largo, con estribo, como varias de las presentes en el arte rupestre de Agua Caliente de Rachaite (Otonello y Lorandi 1987). Palas similares hemos hallado en diversos sectores del sur de Pozuelos, tanto en campos de cultivo como en el interior de recintos domésticos (Ávalos 2010).

Tampoco los morteros, conanas y manos de moler presentan rasgos especiales. Lo que es absolutamente destacable es la cantidad de estos implementos hallados en
Moreta, algo poco común en la cuenca. A pesar de las intensas prospecciones que hemos realizado en el área, y de haber excavado 14 recintos completos, casi todos ellos asociados a estructuras de cultivo, hemos hallado tan solo un fragmento de conana y una mano de moler en el resto del sur de Pozuelos.

Las evidencias de actividades agrícolas son muy abundantes en el asentamiento, por lo que no cabe duda de que gran parte de sus habitantes se dedicaba a la producción agrícola. Suponemos que los espacios cultivados han sido los localizados al sur de Moreta. La mayor parte de la infraestructura agrícola exhibe características muy homogéneas (morfología y tamaño de las estructuras, atributos de los muros, disposición en el terreno, etc.), habiendo sido probablemente construida respondiendo a una planificación previa. De igual modo, las características de los líquenes presentes en los muros también sugieren una construcción relativamente sincrónica. Suponemos que estos sectores habrían sido preparados durante época incaica, bajo el auspicio del Estado. No hay en el sur de Pozuelos ni en la cuenca de Santa Catalina otro lugar con este tipo de infraestructura, ni a esta escala. Por el contrario, en las 
estructuras agrícolas emplazadas en la ladera más cercana al poblado chicha se observan cierta variabilidad morfológica, diversidad en las técnicas constructivas y posibles remodelaciones. Todo parece indicar que serían el resultado de varios eventos constructivos.

De todo esto se desprende que durante época inka, parte de los habitantes del poblado habrían estado de alguna manera involucrados en las tareas agrícolas desarrolladas en esos campos, fundamentalmente en los sectores mencionados en primer término. Sin embargo, los habitantes anteriores a la anexión de estos territorios al Imperio también desarrollaron actividades agrícolas en el lugar. En un sondeo que hemos hecho en un recinto de una vivienda de patrón chicha hallamos tres palas sobre el piso, y el fechado radiocarbónico resultó preincaico $\left(890 \pm_{70} \mathrm{AP}\right.$, o sea 1038-1280 cal. AD, con 2 sigma ${ }^{5}$ ). En un sondeo excavado en un basurero del asentamiento también hemos hallado un fragmento de pala, más antiguo aún que las encontradas en el recinto (Pérez Pieroni y Angiorama 2016). Todo esto indica que las actividades agrícolas se iniciaron antes del Tawantinsuyu. Es posible que parte de las tierras localizadas en la ladera más cercana al asentamiento hayan sido cultivadas ya en aquella época, y que luego el Estado las haya acondicionado y ampliado con la infraestructura necesaria para aumentar la producción.

Los objetos metálicos presentan características similares a otros hallados en la región. Lo que resultó poco común es el hallazgo de la cadena, también con cobre como metal base. Se trata de una pieza de raigambre europea, morfológicamente muy similar a otra hallada por Alfaro en Doncellas, aunque en este último caso fabricada con hierro (Alfaro 1981-82). El hallazgo no debe sorprender considerando que, tal como hemos propuesto de acuerdo a la documentación histórica disponible, existe la posibilidad de que Moreta haya sido utilizado como lugar de asentamiento y refugio indígena en época colonial, e incluso como lugar de acampe y pernocte por parte de las primeras huestes españolas que ingresaron al actual territorio argentino.

Lo que sigue siendo notable, como hemos señalado en otras oportunidades, es la gran escasez de objetos metálicos que se observan en los asentamientos prehispánicos

5 Calibration data set: shcali3.14c (Hogg et al. 2013). de la Puna de Jujuy, en relación a áreas vecinas (como la Quebrada de Humahuaca y el valle del Río Grande de San Juan). A ello se suma la casi total ausencia de evidencias de producción metalúrgica prehispánica local, a pesar de tratarse de una región donde abundan las fuentes de minerales de cobre, estaño, oro y plata, los cuatro metales principales para los habitantes antiguos de los Andes (Angiorama y Becerra 2014). Moreta no parece haber sido la excepción en este sentido.

Con respecto a los materiales cerámicos, es notable la cantidad de recipientes hallados en Moreta correspondientes al estilo Yavi-chicha, muchos de ellos con morfologías incaicas, que han sido vinculados tanto con los chicha preincaicos como con los contemporáneos a la expansión imperial, momento en el que adaptaron las morfologías cuzqueñas a sus prácticas de manufactura y estilos decorativos. En ningún otro sitio del sur de Pozuelos, considerando tanto el material fragmentario como las piezas completas de colecciones, se encuentran estos recipientes en tal cantidad. Por otro lado, si bien se han hallado elementos que pueden corresponder a morfologías presentes en el estilo Casabindo, éstos son escasos. En gran parte están relacionados a actividades textiles, estando ausentes las vasijas y tinajas con morfologías y atributos decorativos más típicos.

Habiendo analizado previamente otras colecciones de museos con materiales cerámicos de la región puneña, podemos realizar una comparación de las morfologías y estilos presentes en diferentes asentamientos. Los grandes sitios cuya cerámica hemos estudiado son Doncellas y Queta, donde Casanova excavó contextos funerarios (Casanova 1943), y el Pukara de Rinconada, donde Boman realizó tareas de excavación tanto en recintos habitacionales como en tumbas localizadas en grutas de la mesada del Pukara y alrededores (Boman 1908). Como mencionamos, no sabemos con certeza dónde excavó Márquez Miranda en Moreta, por lo que nos arriesgamos a comparar contextos que no cumplieron funciones semejantes. A partir de lo observado en el campo, suponemos que se ha limitado al sector del poblado con arquitectura chicha. Sin embargo, esto no quiere decir que el material provenga de contextos domésticos, dado que sabemos de la existencia de enterratorios bajo los pisos de ocupación. De todas maneras, la existencia de piezas completas sobre las cuales 


\begin{tabular}{|c|c|c|c|c|}
\hline & Moreta & Doncellas & Queta & Pukara de Rinconada \\
\hline 1.1 plato & $1,5 \%$ & $0,0 \%$ & $0,0 \%$ & $0,0 \%$ \\
\hline 1.2 fuente & $1,5 \%$ & $0,0 \%$ & $0,0 \%$ & $0,0 \%$ \\
\hline 1.3 escudilla o puco & $24,2 \%$ & $37,5 \%$ & $20,0 \%$ & $6,7 \%$ \\
\hline 1.4 escudilla honda & $9,1 \%$ & $8,3 \%$ & $22,5 \%$ & $13,3 \%$ \\
\hline 1.5 cuenco & $1,5 \%$ & $0,0 \%$ & $0,0 \%$ & $0,0 \%$ \\
\hline 1.6 vaso & $6,1 \%$ & $8,3 \%$ & $5,0 \%$ & $13,3 \%$ \\
\hline 1 abiertas indeterminadas & $3,0 \%$ & $0,0 \%$ & $0,0 \%$ & $0,0 \%$ \\
\hline 2.1 vasija & $7,6 \%$ & $29,2 \%$ & $22,5 \%$ & $0,0 \%$ \\
\hline 2.1 taza & $1,5 \%$ & $4,2 \%$ & $0,0 \%$ & $0,0 \%$ \\
\hline 2.2 tinaja & $0,0 \%$ & $4,2 \%$ & $0,0 \%$ & $0,0 \%$ \\
\hline 2.3 botella & $1,5 \%$ & $4,2 \%$ & $17,5 \%$ & $26,7 \%$ \\
\hline 2.3 aríbalo/aribaloide & $7,6 \%$ & $4,2 \%$ & $0,0 \%$ & $0,0 \%$ \\
\hline 2 cerradas indeterminadas & $6,1 \%$ & $0,0 \%$ & $0,0 \%$ & $26,7 \%$ \\
\hline Miniaturas & $1,5 \%$ & $0,0 \%$ & $0,0 \%$ & $13,3 \%$ \\
\hline Formas varias & $3,0 \%$ & $0,0 \%$ & $12,5 \%$ & $0,0 \%$ \\
\hline Indeterminadas & $24,2 \%$ & $0,0 \%$ & $0,0 \%$ & $0,0 \%$ \\
\hline
\end{tabular}

Tabla 2. Porcentajes de recipientes correspondientes a las diferentes categorías morfológicas para cada una de las colecciones analizadas.

se puede obtener información comparable, nos permite realizar una primera aproximación a las similitudes y diferencias en las formas y estilos decorativos presentes en los sitios mencionados, a fin de comenzar a contextualizar a Moreta en el panorama regional. Para Doncellas y Queta hemos relevado los recipientes depositados en el Instituto Interdisciplinario Tilcara: son 24 para el primer sitio y 40 para el segundo. ${ }^{6}$ Los recipientes cerámicos obtenidos por Boman en el Pukara de Rinconada son solo 15 y se encuentran depositados en el Musée du Quai Branly (París).

En la Tabla 2, observamos una comparación de las morfologías presentes en las diferentes colecciones analizadas. Los totales han sido trasladados a porcentajes, dada la diferencia en cantidad de piezas para los distintos sitios en comparación. Primeramente, observamos que la diversidad morfológica en Moreta es mayor que en el resto de los sitios analizados. Casi todas las clases morfológicas definidas en la literatura arqueológica están re-

6 Se trata de solo una parte de la colección obtenida por Casanova en los sitios de Doncellas y Queta. El resto del material se encuentra depositado en el Museo Etnográfico Ambrosetti, de la ciudad de Buenos Aires. presentadas por al menos un recipiente, exceptuando las tinajas, lo que no sucede en lo demás sitios.

Podemos notar también que son importantes para todos los sitios la cantidad de recipientes abiertos, particularmente las escudillas o escudillas hondas. Entre las piezas cerradas se observan diferencias notables, dado que en los sitios de Doncellas y Queta son importantes las cantidades de vasijas, que son mucho más escasas en Moreta. Por otro lado, el porcentaje de botellas es mayor en Queta y el Pukara de Rinconada, aunque en Moreta tenemos presentes los aríbalos y aribaloides (incluyendo puchuelas o aisanas) que solo se encuentran representados en Doncellas en baja cantidad, y ausentes en los demás contextos.

Por otro lado, hemos observado diferencias en los estilos identificados para las colecciones bajo estudio, información que se ha sintetizado en la Tabla 3. La cantidad de recipientes sin decoración, con las superficies alisadas o pulidas, es grande en los sitios de Moreta y Queta, pero no así en el resto de los asentamientos analizados. Los pucos interior negro pulido están presentes en todas las colecciones, aunque son más abundantes en Doncellas y Queta. 
Moreta, “pueblo de yndios Chichas y tAmbo del yngA" (PunA de Jujuy, argentina)

\begin{tabular}{|c|c|c|c|c|}
\hline & Moreta & Doncellas & Queta & Pukara de Rinconada \\
\hline Ordinario alisado/pulido & $33,3 \%$ & $4,2 \%$ & $29,7 \%$ & $0,0 \%$ \\
\hline Casabindo & $9,1 \%$ & $33,3 \%$ & $27,0 \%$ & $13,3 \%$ \\
\hline PINP & $4,5 \%$ & $12,5 \%$ & $10,8 \%$ & $6,7 \%$ \\
\hline Yavi-chicha & $27,3 \%$ & $25,0 \%$ & $16,2 \%$ & $6,7 \%$ \\
\hline Yavi-inka & $7,6 \%$ & $0,0 \%$ & $8,1 \%$ & $0,0 \%$ \\
\hline Inka provincial & $10,6 \%$ & $12,5 \%$ & $2,7 \%$ & $6,7 \%$ \\
\hline No locales & $4,5 \%$ & $8,3 \%$ & $0,0 \%$ & $13,3 \%$ \\
\hline Indeterminados & $3,0 \%$ & $4,2 \%$ & $5,4 \%$ & $53,3 \%$ \\
\hline
\end{tabular}

Tabla 3. Porcentajes de recipientes correspondientes a los diferentes estilos decorativos identificados para cada una de las colecciones analizadas.

Las diferencias más notables se dan al comparar los porcentajes de los dos estilos morfológicos y decorativos definidos en la literatura arqueológica para la Puna oriental de Jujuy. Por un lado, en Moreta el alto porcentaje de recipientes y fragmentos cerámicos vinculables al estilo Yavichicha es un aspecto a destacar, que lo diferencia de los sitios que hemos analizado hasta la fecha para la porción sur de la cuenca de la laguna de Pozuelos, tanto a partir del material fragmentario como de las colecciones que estamos comparando. En Doncellas, el porcentaje de piezas asignables al estilo Yavi-chicha también es alto, pero si a las de Moreta sumamos las Yavi-chicha con morfología inka el porcentaje es mucho mayor (35\%). En Doncellas, Queta y Pukara de Rinconada son más abundantes los materiales con morfologías, decoración o atributos decorativos relacionados con el estilo Casabindo (Pérez Pieroni 2013). Si bien en Moreta hay algunas piezas de este estilo, como los vasos chatos o el recipiente con asa interna, no están presentes las típicas vasijas con cuellos cilíndricos y subcilíndricos con decoración Casabindo negro sobre rojo o tricolor, ni otras formas características (Albeck 2001), como ya hemos mencionado al comparar las morfologías.

Llama la atención la falta de botellas globulares con asas "asimétricas" en la colección de Moreta, que han sido consideradas como una de las piezas más características del estilo Yavi-chicha. Sin embargo, recientemente Ávila (2013) ha destacado que estas piezas son escasas en general en las muestras por ella analizadas y, dado que se las encuentra casi exclusivamente en contextos funerarios, considera que son piezas correspondientes a esta esfera y no a las actividades cotidianas.
Las piezas cerámicas vinculables a la presencia incaica en la región son más abundantes en Moreta que en los otros asentamientos analizados. En todas las colecciones estudiadas están presentes las piezas Yavi-chicha con morfologías incaicas u otros estilos Inka provinciales (Calderari y Williams 1991), pero en Moreta se suman las piezas de morfología aribaloide, que no habían sido registradas previamente por nosotros en los demás sitios arqueológicos (Pérez Pieroni 2013). Por otro lado, la vinculación recurrente de morfologías incaicas con decoración del estilo Yavi-chicha, tanto en los sitios analizados por nosotros, como en otros sitios del noroeste argentino (Williams y Cremonte 1997), y la ausencia de piezas con influencia inka relacionables al estilo Casabindo, pueden ser indicativas de la existencia de diferentes tipos de relaciones entre el Imperio y los grupos que produjeron esas cerámicas.

Los elementos señalados vienen a reforzar algunas hipótesis que hemos ido generando a lo largo de nuestras tareas en el sur de Pozuelos. Primeramente, que dentro de los estilos puneños, mientras observamos que en época inka los alfareros que manufacturaban el estilo Yavichicha incorporaron morfologías incaicas, no ocurre lo mismo con los materiales del estilo Casabindo, para los que hasta la fecha no conocemos piezas de morfología inka con sus atributos decorativos o tecnológicos. Asimismo, es frecuente el registro de materiales del estilo Yavi-chicha, en baja proporción, en sitios del área del sur de Pozuelos y de la cuenca Miraflores-Guayatayoc, tanto en contextos domésticos como funerarios. No ocurre lo mismo a la inversa en los sitios que hemos analizado para el área de dispersión del estilo Yavi-chicha, donde no 
se registran los recipientes cerámicos característicos del estilo Casabindo, exceptuando solamente los vasos chatos y la base con asa interna que aquí hemos mencionado. Estas particularidades observadas en la cerámica quizás nos estén indicando que, si bien hubo relaciones entre estos grupos entre sí, y con el Imperio inka, las mismas pudieron ser de diferente carácter e intensidad, con un flujo diferencial de objetos, ideas y/o modos de hacer.

\section{* Moreta y su relevancia para la COMPRENSIÓN DE LOS PROCESOS SOCIALES} OCURRIDOS EN LA PUNA DURANTE LOS SIGLOS XIII AL XVI

Si tal como proponemos el sitio arqueológico descripto corresponde al Moreta mencionado por Matienzo en su carta, efectivamente habría sido el asentamiento chicha más meridional de los vinculados al ramal del Qhapaq Nan que ingresaba al actual Noroeste Argentino por la Puna central de Jujuy (más meridional incluso que Ichira/Pozuelos; señalado por Albeck 2008-2010). La información arqueológica disponible así lo indica. Nuestras intensas prospecciones en el sur de la cuenca de Pozuelos no han dado como resultado el hallazgo de otro poblado con arquitectura chicha más al sur, y, como hemos señalado, la proporción en la que se encuentra la cerámica chicha en nuestras recolecciones superficiales ${ }^{7}$ y en la colección conformada por las excavaciones de Márquez Miranda en Moreta, difiere de las tendencias que este estilo sigue en asentamientos localizados más al sur (como el Pukara de Rinconada, Doncellas y Queta; Pérez Pieroni 2013). En todos los sitios prospectados y analizados por nosotros en el sur de Pozuelos y por Zaburlín (2014) en la cuenca de Miraflores-Guayatayoc, la cerámica Yavi es un porcentaje muy pequeño de las muestras totales. Las evidencias sugieren que el detalle del oidor Matienzo de sumar a la mención del tambo inka de Moreta la información acerca de la existencia de un poblado chicha vinculado a él resultó acertada, y pudo deberse precisamente a que se trataba de una condición que no volvía a repetirse camino adelante. En este contexto, resulta sumamente interesante un elemento que desconocíamos hasta ahora: la existencia de un asentamiento de carácter defensivo junto al poblado chicha, desde el cual se visualiza sin

7 De acuerdo a identificaciones preliminares, ya que los materiales obtenidos por recolección superficial y mediante las excavaciones realizadas en los últimos años se encuentran aún bajo estudio. obstáculos el cercano Pukara de Rinconada, el poblado principal de sus vecinos casabindo-cochinoca en la cuenca de Pozuelos (Figura 10).

El hecho de que dos de los escasísimos pukaras conocidos para la Puna de Jujuy (Ruiz y Albeck 1997) se encuentren frente a frente, uno asociado a evidencias vinculadas al fenómeno chicha y el otro asociado a elementos relacionados con el fenómeno casabindocochinoca, convierten a este sector del altiplano en un territorio único para el estudio de los procesos sociales que la "edad de los Auqa Runa" (Guaman Poma de Ayala 1980 [1615]) disparó en las sociedades que habitaron el actual Noroeste Argentino, antes y después de su anexión al Tawantinsuyu. El estudio de este sitio nos permitirá explorar el tenor de las relaciones entre ambos grandes grupos durante los Períodos de Desarrollos Regionales e Inka, de las que no sabemos demasiado hasta el momento. Investigaciones previas propias y de otros investigadores nos están mostrando la existencia de vínculos quizás más profundos que los de simples actos de intercambio o enfrentamiento, más bien una multiplicidad de lazos que involucrarían también la dimensión de las prácticas tecnológicas y estilísticas.

Estas vinculaciones profundas que observamos entre estos grupos para los Períodos de Desarrollos Regionales e Inka también han sido identificadas por Palomeque $(2006,2010,2013)$ en sus investigaciones acerca de la presencia chicha en la Puna de Jujuy durante los siglos XVI y XVII, a las que nos hemos referido líneas atrás. En este cierre nos interesa particularmente retomar que la mencionada autora plantea que durante el siglo XVI existía una estrecha relación entre la parcialidad sur de los chichas y los Casabindo-Cochinoca, que parecería perder fuerza luego de la reducción de los primeros en Talina, en 1573. Sustenta esta afirmación en los vínculos de parentesco que habrían tenido ambos grupos, siendo un señor principal chicha, Curotare, el padre de la esposa principal del curaca del valle de Casabindo en 1557, y habiendo sido el mallku principal de los chicha en ese momento quien auspició las negociaciones de paz de los grupos puneños con los españoles en ese año (Palomeque 2013: 244). Por otra parte, en la sublevación de 1563, los chicha del sur se habrían unido a los casabindo-cochinoca y a otras poblaciones del Tucumán (Palomeque 2013: 245). 


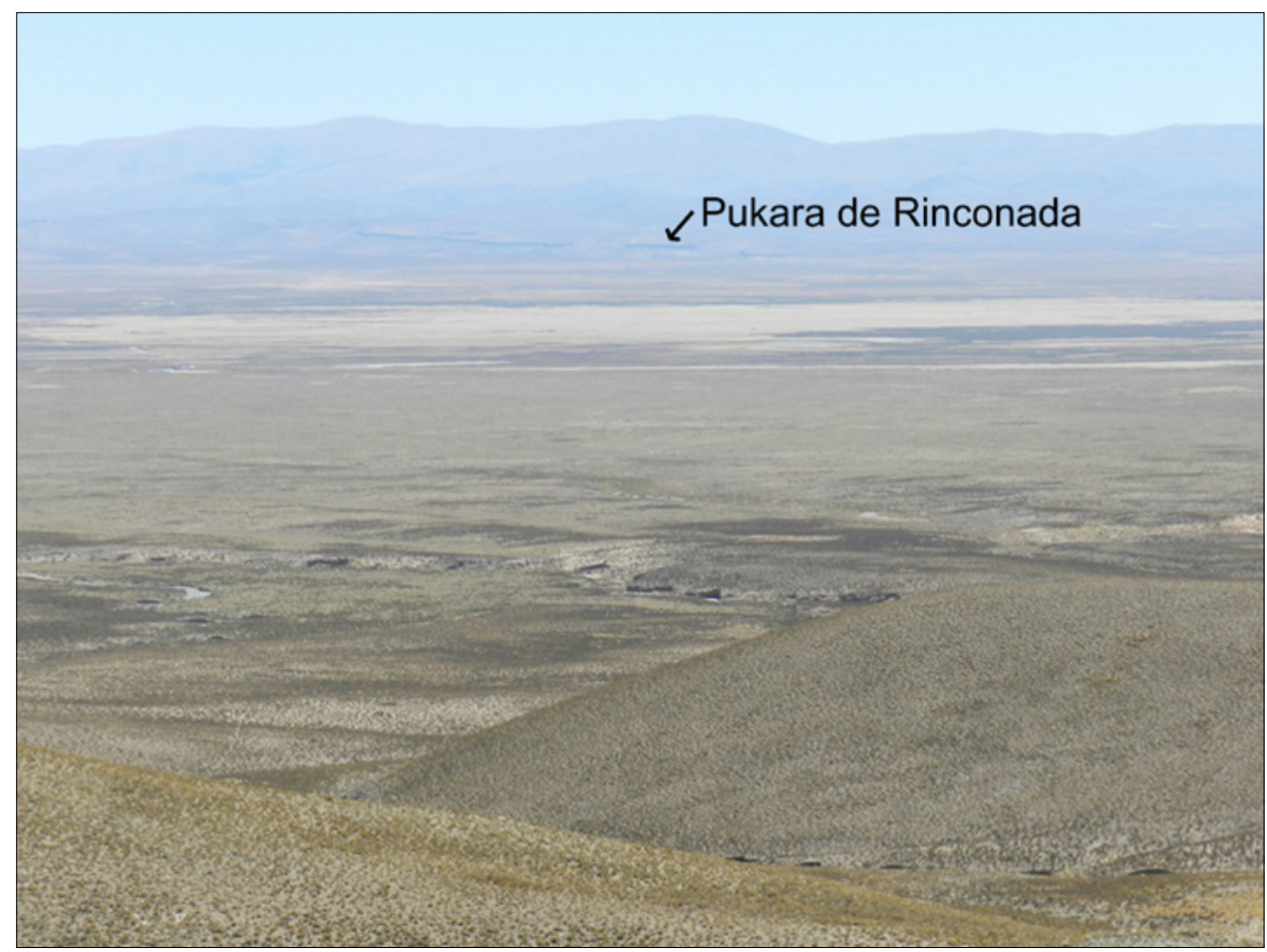

Figura 1o. Vista del Pukara de Rinconada desde el sector alto de Moreta.

Es en esta dirección, entonces, en la que estamos profundizando los trabajos arqueológicos de campo en Moreta, los análisis de laboratorio de las evidencias recuperadas, y el estudio de la documentación histórica disponible y de las colecciones resguardadas en museos.

Agradecimientos Agradecemos a Julio Ávalos por indicarnos la existencia de la Colección Moreta, y a Beatriz
Ventura y Ana María Fernández por los datos que nos brindaron acerca de sus características. Un especial reconocimiento y recuerdo agradecido al Dr. Rodolfo Raffino, quien nos permitió el acceso a la colección. Damos las gracias también a Ana Igareta, Jorge Kraideberg, Gabriel Alarcón, Guillermina Couso y Jorgelina Collazo, quienes nos facilitaron las piezas para su relevamiento. Ninguno de ellos es responsable por las opiniones vertidas en este artículo.

\section{* Referencias citadas}

ALBECK, M. E. 2001. La puna argentina en los períodos medio y tardío. En Historia Argentina Prehispánica. E. Berberián y A. Nielsen (Eds.), pp. 347-388. Editorial Brujas, Córdoba, Argentina.

ALBECK, M. 2008-2010. Poblados arqueológicos de la Puna de Jujuy como topónimos en los siglos XVI y XVII. Cuadernos del Instituto Nacional de Antropología y Pensamiento Latinoamericano 22: 7-16.

ALBECK, M. E. y M. S. RUIZ. 2003. El Tardío en la Puna de Jujuy: Poblados, Etnias y Territorios. Cuadernos de la Facultad de Humanidades y Ciencias Sociales 20: 199-219.
ALBECK, M. E. y S. PALOMEQUE. 2009. Ocupación española de las tierras indígenas de la puna y "raya del Tucumán" durante el temprano período colonial. Memoria Americana 17-2: 173-212.

ALFARO, L. C. 1981-82. Materiales arqueológicos poshispánicos en la cuenca del río Doncellas. Provincia de Jujuy. Relaciones de la Sociedad Argentina de Antropología XIV (2): 81-83.

ANGIORAMA, C. I. y M. F. BECERRA. 2014. “Como en ella jamás ha habido minas..." Minería y metalurgia en la Puna de Jujuy durante momentos prehispánicos tardíos. Relaciones de la Sociedad Argentina de Antropología XXXIX (2): 313-332. 
ÁVALOS, J. C. 1998. Modos de uso de implementos agrícolas de la Quebrada de Humahuaca y Puna a través del análisis de huellas de desgaste. En Los Desarrollos Locales y sus Territorios: Arqueología del NOA y Sur de Bolivia, B. Cremonte (Comp.), pp. 285-303. Universidad Nacional de Jujuy, San Salvador de Jujuy.

ÁVALOS, J. C. 2010. Vida útil y mutabilidad morfológica de los implementos de labranza agrícola: las formas "típicas" y "atípicas" del período tardío de la Puna oriental (Pcia. de Jujuy, Argentina). Actas del XVII Congreso Nacional de Arqueología Argentina, Tomo IV: 1615-1620. Universidad Nacional de Cuyo, Mendoza.

ÁVILA, M. F. 2008. Un universo de formas, colores y pinturas. Caracterización del estilo alfarero yavi de la puna nororiental de Jujuy. Intersecciones en Antropología 9: 197-212.

ÁVILA, M. F. 2013. Estabilizar la experiencia material: diferencias y similitudes contextuales de la alfarería yavi-chicha (frontera argentino-boliviana, siglos XI a XVI). Relaciones de la Sociedad Argentina de Antropología XXXVIII (2): 377-399.

BALFET, H., M. F. FAUVET-BERTHELOT y S. MONZÓN. 1992. Normas para la Descripción de Vasijas Cerámicas. Centre D’Études Mexicaines et Centraméricaines, México D.F.

BOMAN, E. 1908. Antiquités de la Région Andine de la République Argentine et du Désert d'Atacama. Tomo II. Librairie H. Le Soudier, Imprimerie Nationale, Paris.

CALDERARI, M. y V. WILLIAMS. 1991. Reevaluación de los estilos cerámicos incaicos en el Noroeste Argentino. En El imperio Inka. Actualización y perspectivas y registros arqueológicos y etnohistóricos, Comechingonia, vol. II: 73-96.

CARRIZO, J. A. 2009 [1935]. Cancionero Popular de Jujuy. Universidad Nacional de Jujuy, Jujuy.

CASANOVA, E. 1943. Comunicación acerca del Yacimiento de Doncellas. Boletín de la Sociedad Argentina de Antropología 5-6: 80-81.

CREMONTE, M. B., I. L. BOTTO, A. M. DÍAZ, R. VIÑA y M. E. CANAFOGLIA. 2007. Vasijas Yavi-Chicha: distribución y variabilidad a través del estudio de sus pastas. Actas del XVI Congreso Nacional de Arqueología Argentina, tomo II: 189-193. Jujuy.

ESTRUCH, D. 2013. Administración de la justicia y conflictos jurisdiccionales en el Jujuy colonial (siglos XVI y XVII). En El ocaso del imperio. Sociedad y cultura en el centro-sur andino, A. M. Lorandi (Comp.), pp. 125-152. Antropofagia, Buenos Aires.

GONZÁLEZ, A. R. 1963. Problemas Arqueológicos de la Puna Argentina. En A Pedro Bosch Gimpera en el septuagésimo aniversario de su nacimiento, pp. 373-384. México.
GUAMAN POMA DE AYALA, F. 1980 [1615]. Nueva Coronica y Buen Gobierno. Siglo XXI Editores, México D.F.

HOGG, A. G., P. QUAN HUA, G. BLACKWELL, C. E. BUCK, T. P. GUILDERSON, T. J. HEATON, M. NIU, J. G. PALMER, P. J. REIMER, R. W. REIMER, C. S. M. TURNEY, S. R. H. ZIMMERMAN. 2013. SHCali3 Southern Hemisphere calibration, O-50,000 years cal. BP. Radiocarbon 55 (4): 1889-1903.

KRAPOVICKAS, P. 1965. La Cultura de Yavi. Una nueva entidad cultural puneña. Etnia núm. 2:9-10.

KRAPOVICKAS, P. 1968. Subárea de la Puna Argentina. Actas y Memorias del XXXVII Congreso Internacional de Americanistas, tomo 2: 236-271. Buenos Aires.

KRAPOVICKAS, P. 1975. Algunos tipos cerámicos de Yavi Chico. Actas y trabajos del Primer Congreso Nacional de Arqueología Argentina (Rosario, 1970). Buenos Aires.

KRAPOVICKAS, P. 1978. Los Indios de la Puna en el Siglo XVI. Relaciones de la Sociedad Argentina de Antropología, vol. XII: 71-93.

KRAPOVICKAS, P. 1983. Las Poblaciones indígenas históricas del sector oriental de la Puna (un intento de correlación entre la información arqueológica y la etnográfica). Relaciones de la Sociedad Argentina de Antropología 15: 7-24.

KRAPOVICKAS, P., C. P. PLA y S. E. MANUALE. 1989. Reconstruyendo el pasado: La Arqueología, la cultura de Yavi y los chichas. Revista Antropología IV (8): 3-11.

KRAPOVICKAS, P. y S. ALEKSANDROWICZ. 1986-87. Breve visión de la cultura Yavi. Anales de Arqueología y Etnología 41-42: 83-127.

LEVILLIER, R. 1918. Audiencia de Charcas: correspondencia de presidentes y oidores, tomo I. Imprenta de Juan Pueyo, Madrid.

LEVILLIER, R. 1920. Gobernación del Tucumán. Probanzas de méritosy servicios de los conquistadores. Documentos del Archivo de Indias, 15481600. Colección de Publicaciones Históricas de la Biblioteca del Congreso Argentino. Sucesores de Rivadeneyra, Madrid.

NIELSEN, A. E. 1997. Tiempo y Cultura Material en la Quebrada de Humahuaca. 700-1650 d.C. Instituto Interdisciplinario Tilcara, FFyL, UBA.

NIELSEN, A. E., C. I. ANGIORAMA, J. MARYAÑSKI, M. L. LÓPEZ y F. ÁVILA. 2014. Paisajes Prehispánicos Tardíos en San Juan Mayo (Frontera Argentina-Bolivia). Revista Arqueología. En prensa. 
OTTONELLO, M. 1973. Instalación, economía y cambio cultural en el sitio Tardío de Agua Caliente de Rachaite. Publicaciones de la Dirección de Antropología e Historia núm. 1: 23-68. San Salvador de Jujuy.

OTTONELLO, M. y A. M. LORANDI. 1987. Introducción a la arqueología y etnología. Diez mil años de Historia Argentina. EUDEBA, Buenos Aires.

PALOMEQUE, S. 2006. La Historia de los señores étnicos de Casabindo y Cochinoca (1540-1662). Andes 17: 139-194.

PALOMEQUE, S. 2010. Los chichas y las visitas toledanas. Las tieras de los chichas de Talina (1573-1595). PROHAL MONOGRÁFICO. Revista electrónica del Programa de Historia de América Latina, vol. I, núm. 2, Segunda Sección: Surandino Monográfico: Homenaje a Enrique Tandeter. Minería y trabajo indígena, población, familia y sociedades campesinas e historiografía andina. UBA, Buenos Aires. Consultado en http://www.filo. uba.ar/contenidos/investigacion/institutos/ravignani/prohal/ $\mathrm{SM} \_002 \_$Articulos/articulos.html

PALOMEQUE, S. 2013. Casabindos, Cochinocas y Chichas en el siglo XVI. Avances de investigación. En Las Tierras Altas del Área Centro Sur Andina entre el 1000 y el 1600 D.C. TANOA II, M. E. Albeck, M. Ruiz y B. Cremonte (Eds.), pp. 233 a 263. EDIUNJU, Jujuy.

PÉREZ PIERONI, M. J. 2013. Prácticas productivas y tradiciones tecnológicas: la manufactura cerámica prehispánica tardía y colonial en la cuenca sur de Pozuelos y el área de Santa Catalina, puna de Jujuy, Argentina. Tesis para optar al grado de Doctor. Facultad de Ciencias Naturales y Museo, Universidad Nacional de La Plata. Ms.

PÉREZ PIERONI, M. J. y C. I. ANGIORAMA. 2016. Evidencias arqueológicas de los siglos VII a XII AD en el asentamiento de Moreta (puna de Jujuy, Argentina). Trabajo en evaluación. Ms.
RAFFINO, R. 2007. Poblaciones indígenas en Argentina. Urbanismo y proceso social precolombino. Emecé, Buenos Aires.

RAFFINO, R. A., R. J. ALVIS, D. E. OLIVERA y J. R. PALMA. 1986. La instalación inka en la sección andina meridional de Bolivia y extremo boreal de Argentina. En El imperio Inka: actualización y perspectivas, R. A. Raffino (Ed.). Comechingonia, número especial: 63-129.

SICA, G. 2006. Del Pukara al Pueblo de Indios. El proceso de construcción de la sociedad indígena colonial en Jujuy, Argentina, siglo XVII, Tesis para optar al título de Doctor, Universidad de Sevilla. Ms.

VIGNATI, M. A. 1931. Los elementos étnicos del NO argentino. Notas preliminares del Museo de La Plata, vol. I: 115-157.

VITRY, C. 2007. La ruta de Diego de Almagro en el territorio argentino: un aporte desde la perspectiva de los caminos prehispánicos. Revista Escuela de Historia 6 (1): 325-351.

WILLIAMS, V y M. B. CREMONTE. 1997. Mitmaqkuna o circulación de bienes? Indicadores de la producción cerámica como indicadores étnicos. Un caso de estudio en el Noroeste argentino. En El Tucumán Colonialy Charcas, Lorandi (Comp.), pp. 75-86. Facultad de Filosofía y Letras, Universidad Nacional de Buenos Aires, Buenos Aires.

YACOBACCIO, H. 1983. Estudio funcional de azadas líticas del Noroeste Argentino. Arqueología Contemporánea I (1): 3-19.

ZABURLÍN, M. A. 2014. Uso, consumo y circulación de vasijas cerámicas en los pueblos prehispánicos de la cuenca de la laguna de Guayatayoc (puna de Jujuy). Tesis para optar por el grado de Doctor. Facultad de Ciencias Naturales e IML, Universidad Nacional de Tucumán. Ms.

ZANOLLI, C. 2005. Tierra, encomienda e identidad: Omaguaca (15401638). Sociedad Argentina de Antropología, Buenos Aires. 
